\title{
Cystic pancreatic lesions: \\ Can we diagnose them accurately what to look for? FNA marker molecular analysis resection, surveillance, or endoscopic treatment?
}

W. R. Brugge

GI Unit, Blake 452, Massachusetts General Hospital, Boston

\section{Introduction}

Cystic lesions of the pancreas consist of a spectrum of benign, pre-malignant, and malignant malignancies. In the past, cystic neoplasms of the pancreas were thought to be relatively rare, but the widespread use of cross sectional imaging has dramatically increased ability to detect these lesions. Although the vast majority of pancreatic cysts are discovered incidentally, large or invasive lesions may produce sufficient symptoms to cause the patient to seek medical attention.

Cystic neoplasms are often confused or misdiagnosed as pseudocysts or peripancreatic collections of inflammatory fluid that may morphologically mimic cystic neoplasms. Furthermore, the presenting symptoms of pseudocysts may be identical to the symptoms associated with cystic neoplasms.

Cystic neoplasms of the pancreas are traditionally organized by the type of lining epithelium since this feature dominates the risk of malignancy and management [1] (Table 1). There are three types of mucinous lesions, benign mucinous cystadenomas, malignant mucinous cystic lesions, and intra-ductal papillary mucinous neoplasms (IPMNs). The non-mucinous lesions include serous cystadenomas, cystic endocrine tumors and other rare lesions.

\section{Prevalence}

The prevalence of pancreatic cysts has been examined with autopsy examinations of the pancreas in adults without known pancreatic disease. The prevalence of pancreatic cysts found at autopsies in Japan was approximately 73 of 300 autopsies (24.3\%) cases [2]. The prevalence of cysts increased with increasing age of the patient. The cysts were located throughout the pancreatic parenchyma and were not related to chronic pancreatitis. The epithelium of the cysts displayed a spectrum of neoplastic change, including atypical hyperplasia (16.4\%); carcinoma in situ (3.4\%).

Correspondence: William R. Brugge, M.D. · GI Unit · Blake 452 · Massachusetts General Hospital · Boston, MA 02114 - Phone: 001-617-724-3715 - Fax: 001617-724-5996 · E-mail: brugge.william@mgh.harvard.edu 
Table 1

\begin{tabular}{|c|c|c|c|c|c|}
\hline Tumor Type & Gender & Age & Morphology & Type of Epithelium & $\begin{array}{l}\text { Risk of } \\
\text { Malignancy }\end{array}$ \\
\hline Mucinous Cystadenoma & Female & Middle-Aged & Unilocular & Mucinous & Moderate \\
\hline Mucinous Cystic Neoplasm & Female & Middle-Aged & Associated mass & Malignant Mucinous & High \\
\hline Intra-ductal Papillary Mucinous Tumor & Mixed & Elderly & $\begin{array}{l}\text { Unilocular, septated, } \\
\text { associated dilated ducts }\end{array}$ & Papillary Mucinous & Moderate \\
\hline Serous Cystadenoma & Female & Middle-Aged & Microcystic & $\begin{array}{l}\text { Serous } \\
\text { (PAS positive for glycogen) }\end{array}$ & Low \\
\hline Cystic Endocrine Tumor & Mixed & Middle-Aged & Associated mass & Endocrine & Low \\
\hline Solid Cystic Pseudopapillary Tumor & Female & Young & Mixed solid and cystic & Endocrine-like & Low \\
\hline
\end{tabular}

The prevalence of pancreatic cysts in the United States has been estimated in patients undergoing MRI for a number of various medical problems [3]. This review of MRI images revealed about $15-20 \%$ of 1,444 patients had at least one pancreatic cyst. Older patients are more likely to have a cyst than younger patients. Screening abdominal ultrasound in a younger population revealed that $(0.21 \%)$ of the 130,951 adults had a pancreatic cystic lesion [4].

\section{Clinical epidemiology}

Mucinous cystic neoplasms account for approximately $2 \%$ to $5 \%$ of all exocrine pancreatic tumors and are the more common type of cystic tumor. Women are affected far more commonly than men ( $9: 1$ ratio), with a mean age at diagnosis in the fifth decade.

Intraductal papillary mucinous neoplasms are similar to mucinous cystic neoplasms. Their true incidence is uncertain, but estimates range from $1 \%$ to $8 \%$. IPMNs affect men men predominantly, depending on the reported series, and they tend to occur in an older age group than MCNs.

Serous cystadenomas have been estimated to account for about $25 \%$ of all cystic neoplasms of the pancreas [5]. Estimates of the incidence and prevalence vary. Using surgical pathology studies, it has been estimated that serous cystadenomas account for about $1 \%$ to $2 \%$ of all exocrine pancreatic neoplasms.

Serous cystadenomas occur only in adults with a median age in the sixth or seventh decade. The vast majority of patients with serous cystadenomas are female [6]. Traditionally about $1 / 2$ of tumors are discovered as incidental findings during abdominal imaging or surgery or at autopsy.

\section{Risk factors for cystic lesions}

In the vast majority of patients with a cystic lesion, no risk factor is apparent. Von Hippel Lindau (VHL) syndrome is the best-described inherited disorder associated with cystic lesions [7]. In the largest series to date, pancreatic involvement was observed in $122 / 158$ patients $(77.2 \%)$ and included true cysts (91.1\%), serous cystadenomas (12.3\%), neuroendocrine tumors $(12.3 \%)$, or combined lesions (11.5\%).

\section{Pathogenesis}

The pathogenesis of cystic neoplasms of the pancreas is poorly understood. Serous cystadenomas are strongly associated with mutations of the VHL gene, located on chromosome 3p25 [8]. The mutations in the VHL gene probably affect most commonly the centro-acinar cell and result in hamartomatous proliferation of these small cuboidal cells. In one study, $70 \%$ of the sporadic serous cystadenomas studied demonstrated loss of heterozygosity $(\mathrm{LOH})$ at 3p25 with a VHL gene mutation in the remaining allele [9].

Mucinous cystic neoplasms and intraductal papillary mucinous neoplasms (IPMN) probably have a similar pathogenesis. K-ras mutations are present only in mucinous cystic neoplasms and not in serous microcystic adenomas. In addition, $\mathrm{LOH}$ at $3 \mathrm{p} 25$, the chromosomal location of VHL gene, was present in 57\% (8/ 14) of serous microcystic adenomas compared with only $17 \%$ (2/12) of mucinous cystic neoplasms [10]. Mucinous cystic neoplasms frequently contain mutations of the K-ras oncogene and p53 tumor suppressor gene, and the frequency of these mutations increases with increasing degrees of dysplasia in the neoplasm [11]. The frequency of K-ras mutation in mucinous cystic neoplasms is linearly related to the grades of atypia [12]. However, the degree of atypia in IPMT does not seem to correlate with the presence of k-ras mutations. $\mathrm{LOH}$ of the $\mathrm{p} 16$ gene was observed with increasing degrees of histological atypia in IPMN, whereas $\mathrm{LOH}$ of the p53 gene was seen only in invasive carcinomas.

\section{Pathology}

\section{Serous cystadenomas (Fig. 1 )}

Serous cystadenomas are benign, solitary, cystic tumors that lined by small, bland, centro-acinar cells. Although the majority of serous cystadenomas have a microcystic morphology, there are two other variants based on growth pattern: macrocystic and solid. Microcystic serous cystadenomas are composed of multiple small thin-walled cysts with a honeycomb-like appearance on cross section. Microcystic serous cystadenomas may grow to a large diameter over the long-term and the large lesions often have a fibrotic or calcified central scar. Macrocystic serous cystadenomas are composed of far fewer cysts, and the diameter of each cyst varies from microcystic to large cavities [13]. The pres- 


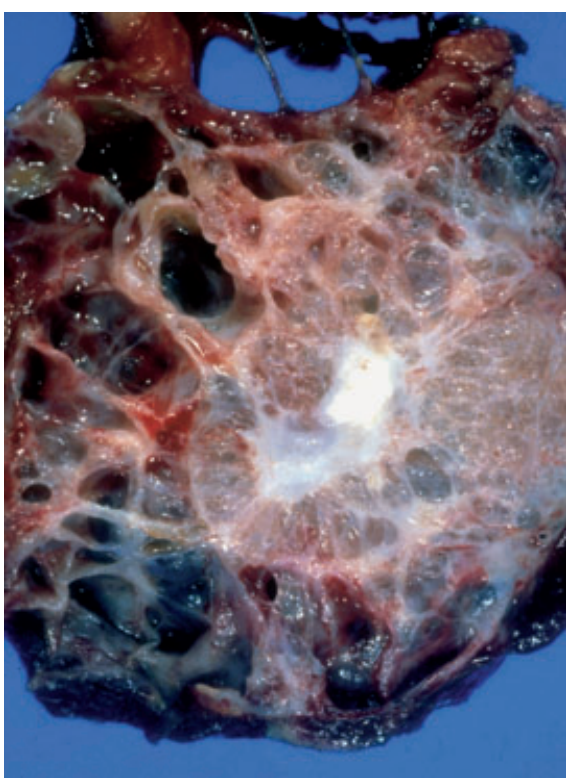

Fig. 1 Gross photograph of a serous cystadenoma.

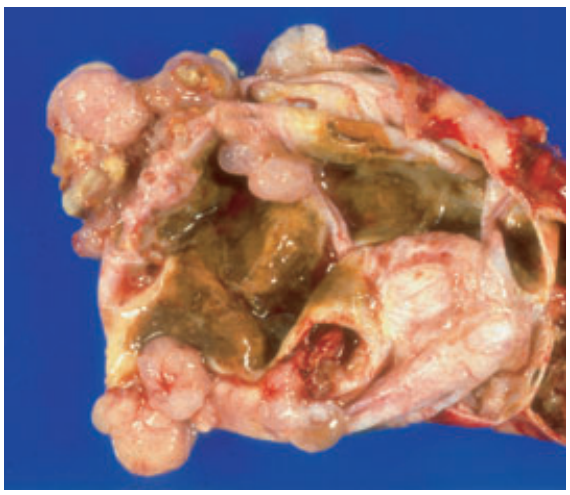

Fig. 2 Gross photograph of a mucinous cystic neoplasm.

ence of discrete, large cystic cavities mimics the appearance of mucinous lesions, particularly IPMT. However, the cyst fluid from serous cystadenomas is non-viscous and may contain blood as a result of the vascular nature of the lesions.

\section{Mucinous cystic neoplasms (Fig. 2)}

Mucinous cystic neoplasms (MCNs) are composed of discrete individual locules that vary in diameter. MCNs are lined by mucinproducing cells in a columnar epithelium. The World Health Organization classification catalogues MCNs into three types, based on the degree of epithelial dysplasia: benign, borderline, and malignant. The degree of atypia of the tumor is classified according to the most advanced degree of dysplasia/carcinoma present.

Mucinous cystic neoplasms of the pancreas often contain a unique, highly cellular (so-called "ovarian") stroma that often contain estrogen and progesterone receptors. It occurs almost exclusively in female patients, although rare cases of MCNs with ovarian stroma in male patients have been encountered. Many authorities have restricted the very definition of MCNs to include only those cystic mucinous tumors that contain ovarian stroma. The cyst fluid from MCNs is often viscous and clear.

IPMNs are similar to MCNs in that they are cystic tumors that secrete mucin. However, IPMNs are characterized by a unique pap- illary epithelium and arise from ductal epithelium. The presence of a papillary neoplasm causes the pancreatic duct to dilate. The degree of ductal ectasia produced varies with degree of mucin production, but duct dilatation great enough to be seen on imaging studies or gross pathologic examination is a diagnostic feature of the diagnosis. Mucin production may be so excessive that mucin will be spontaneously secreted out of the ampulla. The degree of dysplasia exhibited by the epithelium may range from mild to moderate to severe (carcinoma in situ), and the foci of early malignancy may be evident by the presence of mural nodules [14]. The solid malignancies that arise from IPMN are more likely to have papillary features, as compared to typical pancreatic malignancies that arise from the main pancreatic duct [15].

\section{Cystic endocrine neoplasms}

Cystic neoplasms are composed of neuroendocrine tissue. The cystic lesions are not true cysts since they are composed of centralized tumor necrosis. The lesions are rare and comprise $0.5-$ $4 \%$ of all primary pancreatic neoplasms. The classic neuroendocrine cystic tumor is populated with a characteristic small, granular population of cells that are stainable for immunoreactive hormones, chromogranin and synaptophysin [16]. It is rare for the cystic endocrine tumors to produce sufficient hormones to be clinically active. Cystic endocrine tumors are seen in association with Von Hippel-Lindau syndrome [17]. A related cystic lesion, the solid pseudopapillary tumor contains cells with neuroendocrine characteristics [18]. The tumor often contains areas of hemorrhage and necrosis as well as cystic components. These neoplasms exhibit low grade malignant behavior and have an excellent prognosis when resected, but a small percent metastasize.

\section{Clinical presentation}

Most patients with a pancreatic cystic lesion have non-specific symptoms [19]. The cystic lesion is usually found with CT or US imaging performed for the evaluation of another condition. When symptoms are present, the most common presentation is recurrent abdominal pain, nausea, and vomiting as result of mild pancreatitis [19]. Cystic lesions that cause duct compression or involvement of the main pancreatic duct are prone to cause pancreatitis. Chronic abdominal pain and jaundice are a rare presentation of a cystic lesion and suggests a malignancy or a pseudocyst. Patients with a cystic malignancy will present with symptoms and signs similar to pancreatic cancer, i.e. pain, weight loss, and jaundice [20]. Pseudocysts may arise after an episode of acute pancreatitis or insidiously in the setting of chronic pancreatitis and are associated with chronic abdominal pain. It is common for cystic lesions associated with pancreatitis to be diagnosed as pseudocysts and be confused with cystic neoplasms that also cause pancreatitis [21].

\section{Differential diagnosis (Table 2)}

The differential diagnosis of a cystic lesion of pancreas is very wide and often causes confusion. Since the treatment of a pseudocyst and cystic neoplasm are so different, it is incumbent on the clinician to first differentiate between these major categories of lesions. Although it is unusual for a patient with a pseudocyst to present without preceding symptoms, it may occur in mild 
Table 2

\begin{tabular}{llll}
\hline $\begin{array}{l}\text { Type of Lesion } \\
\text { Merous }\end{array}$ & Location & Cytology \\
\hline & Microcystic & Evenly distributed & $\begin{array}{l}\text { Bland } \\
\text { PAS + }\end{array}$ \\
\hline Mucinous & Macrocystic & Tail & Mucinous \\
\hline IPMT & Mixed & Head & Mucinous \\
\hline Pseudocyst & Unilocular & Evenly distributed & Pigmented histiocytes \\
\hline
\end{tabular}

chronic pancreatitis. Evidence of inflammatory changes or calcifications in the pancreas is suggestive of a pancreatic pseudocyst. However, in the initial setting of mild pancreatitis it may be difficult to differentiate between a cystic neoplasm that has caused pancreatitis and a small pseudocyst that has formed as a result of pancreatitis. If a cystic lesion has been present for many years, it is highly likely that the lesion represents a cystic neoplasm. Congenital cysts of the pancreas are rare [22].

Once a pancreatic pseudocyst has been excluded, attention should be focused on the differential between the types of cystic neoplasms. The principal differentiation is between mucinous and serous lesions because the fundamental difference in management is based on the neoplastic potential of mucinous lesions. The non-neoplastic serous cystadenomas may diagnosed on the initial imaging test because their typical microcystic morphology. Once a serous lesion has been confidently diagnosed, the lesion may be followed by serial imaging, looking for evidence of growth of organ impingement. In contrast, the approach to mucinous lesions is quite different. The underlying risk of malignancy or the development of malignancy often results in resection of the lesion. Under some clinical circumstances, such as patients who are at high risk for complications of pancreatectomy, differentiation between benign and grossly malignant mucinous lesions is important. The risk of surgery must be weighed against the risk of malignancy in the decision-making process. The risk of surgery must also take into account the variation in risk that is inherent in the location of the lesion.

\section{Diagnostic methods}

$\mathrm{CT}$ is an excellent test for cystic lesions of the pancreas because of its widespread availability and ability to detect cysts [23] (Fig. 3). MR imaging is used increasingly because of its ability to determine if there is involvement of the main pancreatic duct [24]. Ultrasonography whether performed transabdominally or intraoperatively is generally not helpful [25]. Recently PET scanning has been shown to be positive in a high percentage of malignant cystic lesions [26].

Although seen in less than 20 percent of lesions, demonstration of a central scar by CT or MR is a highly diagnostic feature of a serous cystadenoma [27]. The honey-combed or microcystic appearance of the lesion is commonly used to provide a diagnosis. However, macrocystic serous cystadenomas are difficult to diagnose with cross-sectional imaging because of the morphologic similarities with mucinous lesions $[13,28]$. The presence of mul- tiple small thin-walled cysts is suggestive of Von Hippel Lindau syndrome [29]. Mucinous cystic neoplasms, in contrast, are commonly diagnosed with CT based on the unilocular or macrocystic characteristics [30]. Although not frequently seen, the finding of peripheral calcification by $\mathrm{CT}$ is specific for a mucinous cystic neoplasm. Intraductal papillary mucinous neoplasms (IPMN) may involve the main pancreatic duct exclusively, a side-branch or both. MRCP can demonstrate the diagnostic findings of pancreatic duct dilation, mural nodules, and ductal connection better than ERCP [31]. However, ERCP will can demonstrate the intraductal filling defects, mucin extrusion, and cystic side branches that are associated with IPMN in $70-90 \%$ of patients $[32,33]$.

Despite these imaging features, the ability to accurately diagnose a specific cystic lesion and to determine whether malignancy is present by CT and MR remains uncertain (Fig. 4). The diagnosis of a pancreatic pseudocyst is more dependent upon the clinical history and the associated findings of chronic pancreatitis. Pancreatic pseudocysts appear as unilocular fluid-filled cavities associated with parenchymal changes such as calcifications and atrophy.

Recently endoscopic ultrasound (EUS) has been used to diagnose cystic lesions of the pancreas and guide fine needle aspiration (FNA) [34]. The detailed imaging features of cystic neoplasms by EUS do not appear to be sufficiently accurate to differentiate between benign and malignant cystadenomas unless there is evidence of a solid mass or invasive tumor [35] (Fig. 5). EUS is also very sensitive for detecting IPMN lesions, but imaging alone may not be sufficient for differentiating between benign and ma-

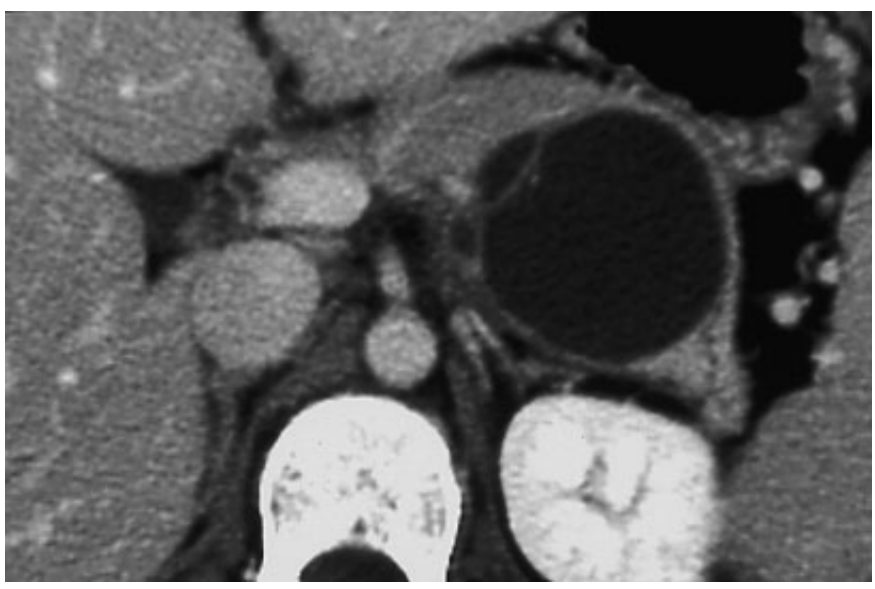

Fig. 3 CT scan of a mucinous cystic neoplasm in the tail of the pancreas. 


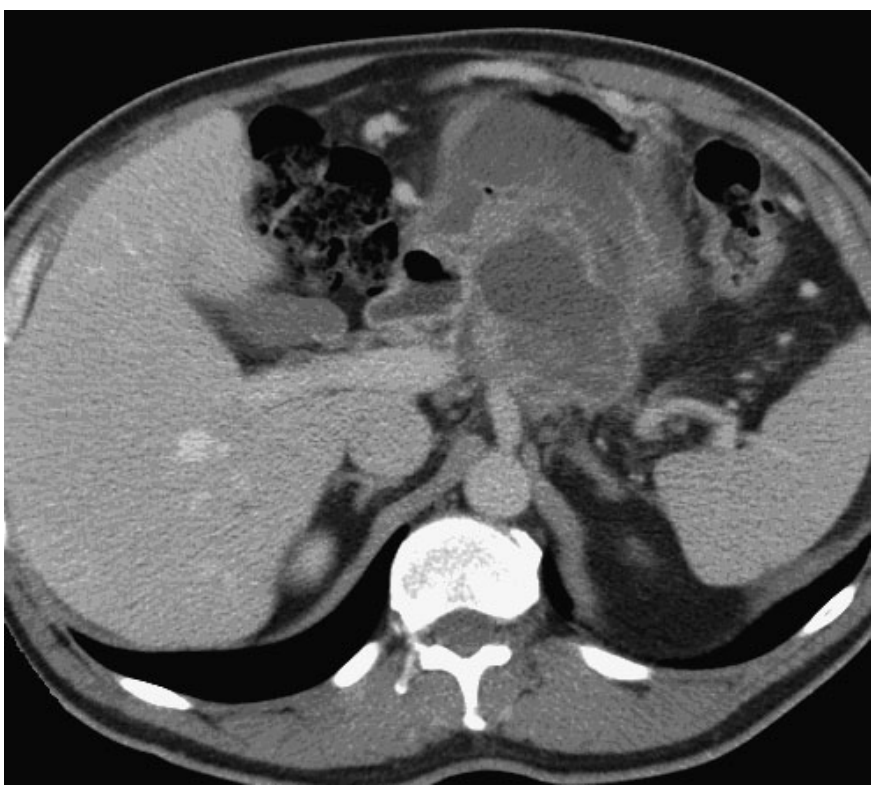

Fig. 4 CT scan of a mucinous cystadenocarcinoma.

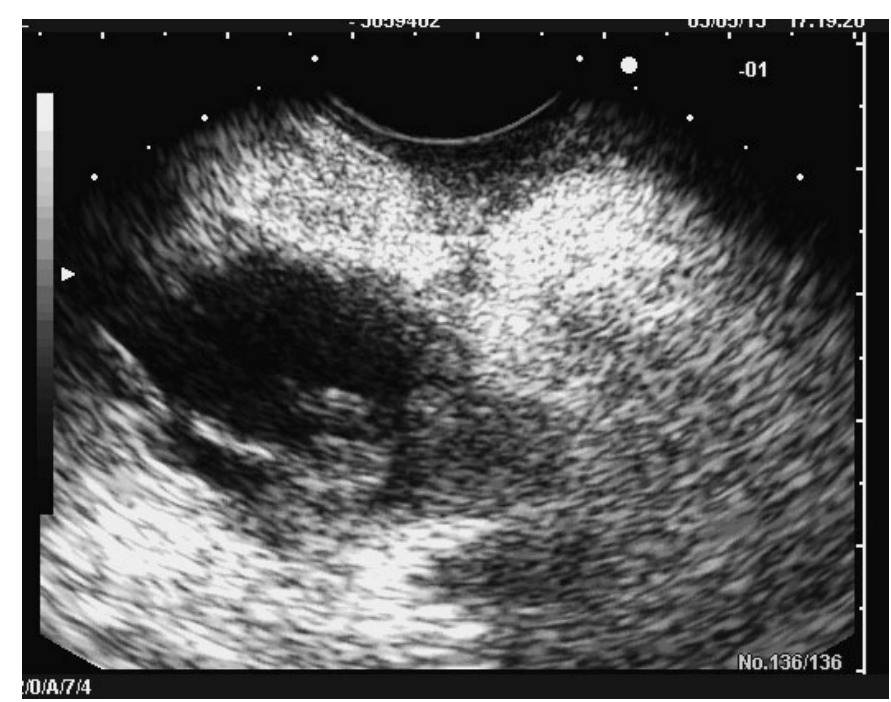

Fig. 5 EUS image of a mucinous cystadenocarcinoma: note the mass in the wall of the cyst.

lignant lesions $[36,37]$. The strength of EUS is its ability to detect and aspirate small cystic lesions with a high level of safety [38]. EUS is more accurate in the evaluation of lesions less than $3 \mathrm{~cm}$ in diameter [39]. The macrocystic variant of serous cystadenomas can be diagnosed with EUS using a combination of a thick cyst wall, the presence of microcysts, and a low cyst fluid CEA [40].

The fluid contents of cystadenomas are often analyzed for cytology [41]. However, the low cellular content of cyst fluid has hampered the use of the cytologic analysis of cyst fluid. Small, cuboidal cells in cytologic specimens are diagnostic of serous cystadenomas. In contrast, mucinous cystadenoma may have large secretory epithelial cells with evidence of mucin secretion or atypia [42]. Only inflammatory cells should be present in the fluid aspirated from pseudocysts.

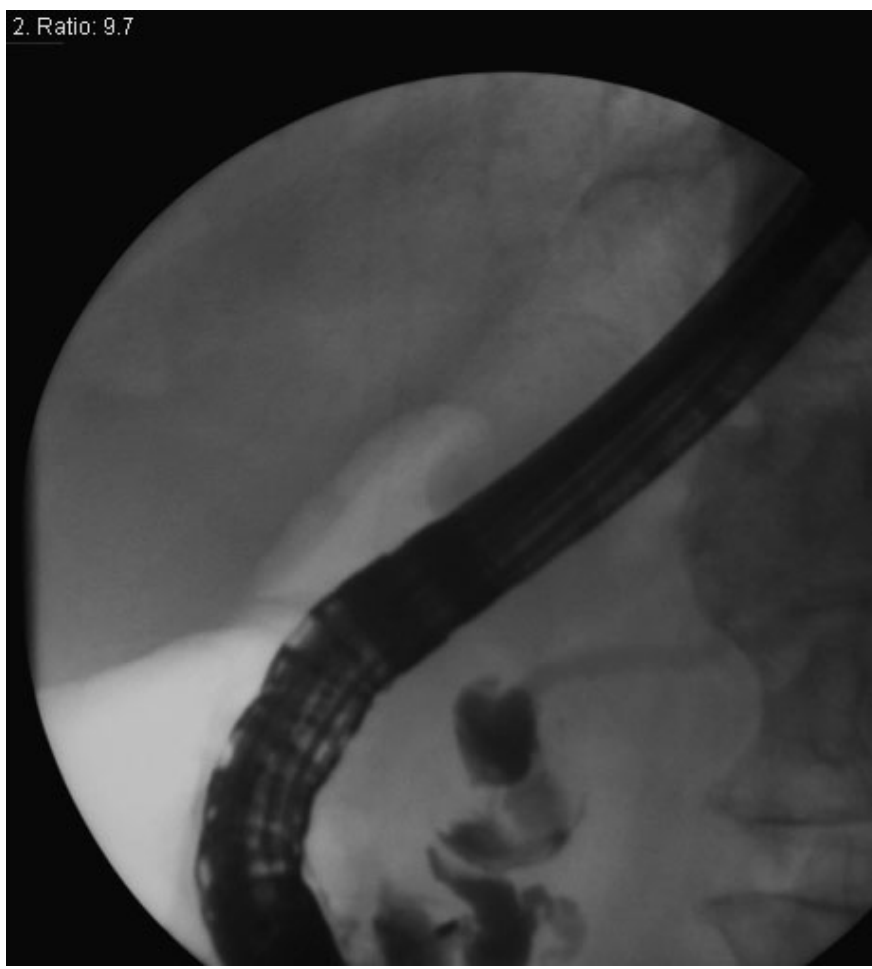

Fig. 6 ERCP of IPMT: Note the dilated and tortuous main pancreatic duct.

A variety of cyst fluid tumor markers have been studied to help differentiate between the major types of cystic neoplasms. Serum 19-9 is elevated in frank cystic malignancies [43]. A number of glycoproteins are present in the epithelium of mucinous neoplasms and are secreted into the cyst fluid [44]. The presence of extracellular mucin in aspirated cyst fluid is moderately predictive of a mucinous neoplasm [45]. Several studies suggest that carcinoembryonic antigen (CEA) or CA 72-4 are useful for identifying mucinous lesions $[46,47]$. These carbohydrate antigens are secreted by the epithelium lining mucinous lesions and may be present in high concentrations. Cyst fluid concentrations of CEA and CA $72-4$ are very low in serous cystadenomas [48]. Despite considerable overlap between mucinous and non-mucinous cysts, cyst fluid CEA is the most accurate marker $[47,49]$. Cyst fluid CEA of less than $5 \mathrm{ng} / \mathrm{ml}$ is highly diagnostic of serous cystadenomas and values greater than 800 are predictive of mucinous lesions [49]. Recently molecular studies of cyst fluid DNA have revealed kRAS, tumor suppressor gene mutations, telomerase activity in mucinous cystic lesions $[11,50]$.

Intra-ductal papillary mucinous neoplasms can be evaluated with endoscopic retrograde cholangio-pancreatography (ERCP) or EUS [51]. Prior to ERCP or EUS, the endoscopic finding of a patulent ampulla filled with mucin is diagnostic of an intraductal papillary mucinous neoplasm. Contrast retrograde pancreatography will demonstrate the characteristic findings of mucinous filling defects within the duct, diffuse ductal dilation, and cystic dilation of side branches [52]. MRCP may be more sensitive for detecting the sidebranch lesions of IPMN [53]. EUS may assist in the detection of malignancy arising from intraductal papillary mucinous neoplasms by demonstrating focal nodules, invasive lesions and guiding fine needle aspiration of suspicious lesions 
Table 3 Use of FNA samples: prioritizing the use of samples

\begin{tabular}{lllll}
\hline Type of lesion & First priority & Second priority & Third priority & Experimental \\
\hline Serous & CEA & Imaging & Fluid cytology & VHL gene testing \\
Mucinous & CEA & Cytology & $\begin{array}{l}\text { Subjective assessment } \\
\text { of viscosity }\end{array}$ & $\mathrm{kRAS}$ \\
& & $\mathrm{LOH}$ analysis & $\mathrm{kRAS}$ \\
Malignant & Tissue cytology & Fluid cytology & $\mathrm{LOH}$ analysis \\
\hline
\end{tabular}

[54]. EUS can also be used to monitor IPMN lesions, looking for increases in the size of cysts and the diameter of the main pancreatic duct [55].

\section{Diagnostic evaluation}

Patients suspected of having a cystic neoplasm of the pancreas should undergo a CT scan with contrast as the initial test. If no lesion is seen in the pancreas, it is very unlikely that a clinically significant neoplasm is present. MR imaging, particularly MRCP, may be substituted for $\mathrm{CT}$ scanning. If the $\mathrm{CT}$ scan demonstrate a diagnostic finding, such as a classic microcystic serous cystadenoma, a malignant cystic mass, or pancreatitis with a fluid collection, no further evaluation is necessary. If the patient is a young woman and there is a solitary, unilocular cystic lesion in the tail of the pancreas, the patient should undergo surgical resection. Indeterminate lesions should undergo EUS with FNA. Aspirated cyst fluid should be analyzed for CEA, cytology, and amylase (Table 3). Preference should be given to sending the fluid for CEA, over cytology in small mucinous lesions. Cytology should be used preferentially in malignant appearing cystic lesions. IPMN lesions should have FNA of cystic lesions, an enlarged pancreatic duct, and focal mass lesions. Cytology should be used preferentially.

\section{Treatment}

Surgical resection is the treatment of choice for pre-malignant cystic neoplasms. The decision to resect a lesion, however, is based on the presence or absence of symptoms, the risk of malignancy, and the surgical risk of the patient. High risk patients with low grade cystic neoplasms may be monitored with periodic CT/MRI scanning or EUS-FNA [56]. Experimentally, high risk patients have been treated with EUS-guided ethanol lavage which safely produces ablation of the cyst epithelium [57]. Small cystic lesions in the elderly can be safely monitored [58].

The increasing safety of surgical resection has prompted the use of surgery for a wider range of lesions [59]. However, serous cystadenomas do not require resection except for relief of symptoms [60]. Since most mucinous cystic neoplasms are located in the tail of the pancreas, a distal pancreatectomy is sufficient for these pre-malignant lesions. Since intraductal papillary mucinous neoplasms invade the pancreas along ductal structures, it is important that frozen section histology be used during surgery to assure negative margins $[61,62]$.

\section{Prognosis}

Cystic neoplasms are slow growing and $19 \%$ will demonstrate an increase in diameter at 16 months [63]. Surgical resection is associated with a morbidity of $27.9 \%$, with a reoperation rate of $7.3 \%$ and a very low mortality rate [6]. The overall 5 -year survival for patients having IPMNs without invasive cancer was $77 \%$, compared with $43 \%$ in those patients with an invasive component [64]. The overall post-operative recurrence rate varies from $7 \%$ to $43 \%$ [65]. Approximately $50 \%$ of patients will have evidence of malignancy in the resected specimen [66]. Similar survival rates are seen in patients with mucinous cystic neoplasms [67]. Side branch lesions arising from IPMN have a better prognosis than main duct IPMN [68]. The worst prognosis is for advanced, transmural adenocarcinomas arising from mucinous lesions; the 5 -year survival is only $30 \%$ for resected lesions.

\section{References}

${ }^{1}$ Brugge WR, Lauwers GY, Sahani D et al. Cystic neoplasms of the pancreas. N Engl J Med 2004; 351: 1218 - 1226

2 Kimura W, Nagai H, Kuroda A et al. Analysis of small cystic lesions of the pancreas. Int J Pancreatol 1995; 18: 197-206

${ }^{3}$ Zhang XM, Mitchell DG, Dohke M et al. Pancreatic cysts: depiction on single-shot fast spin-echo MR images. Radiology 2002; 223: 547 - 553

${ }^{4}$ Ikeda M, Sato T, Morozumi A et al. Morphologic changes in the pancreas detected by screening ultrasonography in a mass survey, with special reference to main duct dilatation, cyst formation, and calcification. Pancreas 1994; 9: 508 - 512

${ }^{5}$ Compton CC. Serous cystic tumors of the pancreas. Semin Diagn Pathol 2000; 17: $43-55$

${ }^{6}$ Bassi C, Salvia R, Molinari E et al. Management of 100 consecutive cases of pancreatic serous cystadenoma: wait for symptoms and see at imaging or vice versa? World J Surg 2003; 27: 319-323

${ }^{7}$ Hammel P. [Diagnostic value of cyst fluid analysis in cystic lesions of the pancreas: current data, limitations, and perspectives]. J Radiol 2000; 81: 487-490

${ }^{8}$ Moore PS, Zamboni G, Brighenti A et al. Molecular characterization of pancreatic serous microcystic adenomas: evidence for a tumor suppressor gene on chromosome 10q. Am J Pathol 2001; 158: 317 - 321

9 Vortmeyer AO, Lubensky IA, Fogt F et al. Allelic deletion and mutation of the von Hippel-Lindau (VHL) tumor suppressor gene in pancreatic microcystic adenomas. Am J Pathol 1997; 151: 951 - 956

${ }^{10}$ Ahmad NA, Kochman ML, Brensinger C et al. Interobserver agreement among endosonographers for the diagnosis of neoplastic versus nonneoplastic pancreatic cystic lesions. Gastrointest Endosc 2003; 58: $59-64$

${ }^{11}$ Khalid A, McGrath KM, Zahid M et al. The role of pancreatic cyst fluid molecular analysis in predicting cyst pathology. Clin Gastroenterol Hepatol 2005; 3: 967-973

12 Yoshizawa K, Nagai H, Sakurai S et al. Clonality and K-ras mutation analyses of epithelia in intraductal papillary mucinous tumor and mucinous cystic tumor of the pancreas. Virchows Arch 2002; 441: 437-443 
${ }^{13}$ Khurana B, Mortele KJ, Glickman J et al. Macrocystic serous adenoma of the pancreas: radiologic-pathologic correlation. AJR Am J Roentgenol 2003; 181: 119-123

14 Tanaka M. Intraductal papillary mucinous neoplasm of the pancreas: diagnosis and treatment. Pancreas 2004; 28: 282 - 288

15 Furuta K, Watanabe H, Ikeda S. Differences between solid and duct-ectatic types of pancreatic ductal carcinomas. Cancer 1992; 69: $1327-$ 1333

${ }^{16}$ Kann P, Bittinger F, Engelbach M et al. Endosonography of insulin-secreting and clinically non-functioning neuroendocrine tumors of the pancreas: criteria for benignancy and malignancy. Eur J Med Res 2001; 6: $385-390$

17 Marcos HB, Libutti SK, Alexander HR et al. Neuroendocrine tumors of the pancreas in von Hippel-Lindau disease: spectrum of appearances at CT and MR imaging with histopathologic comparison. Radiology 2002; 225: 751 - 758

18 Notohara K, Hamazaki S, Tsukayama C et al. Solid-pseudopapillary tumor of the pancreas: immunohistochemical localization of neuroendocrine markers and CD10. Am J Surg Pathol 2000; 24: 1361 - 1371

19 Wiesenauer CA, Schmidt CM, Cummings OW et al. Preoperative predictors of malignancy in pancreatic intraductal papillary mucinous neoplasms. Arch Surg 2003; 138: 610-7; discussion 617-618

${ }^{20}$ Holly EA, Chaliha I, Bracci PM et al. Signs and symptoms of pancreatic cancer: a population-based case-control study in the San Francisco Bay area. Clin Gastroenterol Hepatol 2004; 2: 510 - 517

21 Sand J, Nordback I. The differentiation between pancreatic neoplastic cysts and pancreatic pseudocyst. Scand J Surg 2005; 94: 161 - 164

22 Caillot JL, Rongieras F, Voiglio E et al. A new case of congenital cyst of the pancreas. Hepatogastroenterology 2000; 47: 916-918

${ }^{23}$ Curry CA, Eng J, Horton KM et al. CT of primary cystic pancreatic neoplasms: can CT be used for patient triage and treatment? AJR Am J Roentgenol 2000; 175: 99-103

${ }^{24}$ Fukukura Y, Fujiyoshi F, Hamada $\mathrm{H}$ et al. Intraductal papillary mucinous tumors of the pancreas. Comparison of helical CT and MR imaging. Acta Radiol 2003; 44: 464-471

${ }^{25}$ Kubota K, Noie T, Sano K et al. Impact of intraoperative ultrasonography on surgery for cystic lesions of the pancreas. World J Surg 1997; 21: 72 - 76; discussion 77

${ }^{26}$ Sperti C, Pasquali C, Decet G et al. F-18-fluorodeoxyglucose positron emission tomography in differentiating malignant from benign pancreatic cysts: a prospective study. J Gastrointest Surg 2005; 9: 22 28 ; discussion $28-29$

27 Torresan F, Casadei R, Solmi L et al. The role of ultrasound in the differential diagnosis of serous and mucinous cystic tumours of the pancreas. Eur J Gastroenterol Hepatol 1997; 9: 169-172

${ }^{28}$ Chatelain D, Hammel P, O'Toole D et al. Macrocystic form of serous pancreatic cystadenoma. Am J Gastroenterol 2002; 97: 2566 - 2571

${ }^{29}$ Cheng TY, Su CH, Shyr YM et al. Management of pancreatic lesions in von Hippel-Lindau disease. World J Surg 1997; 21: 307 - 312

30 Sahani D, Prasad S, Saini S et al. Cystic pancreatic neoplasms evaluation by CT and magnetic resonance cholangiopancreatography. Gastrointest Endosc Clin N Am 2002; 12: 657 - 672

31 Sugiyama M, Atomi Y, Hachiya J. Intraductal papillary tumors of the pancreas: evaluation with magnetic resonance cholangiopancreatography. Am J Gastroenterol 1998; 93: 156-159

32 Madura JA, Wiebke EA, Howard TJ et al. Mucin-hypersecreting intraductal neoplasms of the pancreas: a precursor to cystic pancreatic malignancies. Surgery 1997; 122: 786 - 92; discussion $792-793$

33 Azar C, Van de Stadt J, Rickaert F et al. Intraductal papillary mucinous tumours of the pancreas. Clinical and therapeutic issues in 32 patients. Gut 1996; 39: 457 - 464

34 Brugge WR. Evaluation of pancreatic cystic lesions with EUS. Gastrointest Endosc 2004; 59: 698 - 707

${ }^{35}$ Ahmad NA, Kochman ML, Lewis JD et al. Can EUS alone differentiate between malignant and benign cystic lesions of the pancreas? Am J Gastroenterol 2001; 96: 3295-3300

${ }^{36}$ Brandwein SL, Farrell JJ, Centeno BA et al. Detection and tumor staging of malignancy in cystic, intraductal, and solid tumors of the pancreas by EUS. Gastrointest Endosc 2001; 53: 722 - 727

37 Terris B, Ponsot $P$, Paye $F$ et al. Intraductal papillary mucinous tumors of the pancreas confined to secondary ducts show less aggressive pathologic features as compared with those involving the main pancreatic duct. Am J Surg Pathol 2000; 24: 1372 - 1377
${ }^{38}$ Lee LS, Saltzman JR, Bounds B et al. EUS-guided fine needle aspiration of pancreatic cysts: a retrospective analysis of complications and their predictors. Clin Gastroenterol Hepatol 2005; 3: 231 - 236

39 Volmar KE, Vollmer RT, Jowell PS et al. Pancreatic FNA in 1000 cases: a comparison of imaging modalities. Gastrointest Endosc 2005; 61: $854-861$

40 O'Toole D, Palazzo L, Hammel P et al. Macrocystic pancreatic cystadenoma: The role of EUS and cyst fluid analysis in distinguishing mucinous and serous lesions. Gastrointest Endosc 2004; 59: 823-829

${ }^{41}$ Centeno BA, Warshaw AL, Mayo-Smith W et al. Cytologic diagnosis of pancreatic cystic lesions. A prospective study of 28 percutaneous aspirates. Acta Cytol 1997; 41: 972 - 980

42 Recine M, Kaw M, Evans DB et al. Fine-needle aspiration cytology of mucinous tumors of the pancreas. Cancer 2004; 102: 92 - 99

${ }^{43}$ Sperti C, Pasquali C, Guolo P et al. Serum tumor markers and cyst fluid analysis are useful for the diagnosis of pancreatic cystic tumors. Cancer 1996; 78: $237-243$

${ }^{44}$ Yamaguchi K, Enjoji M. Cystic neoplasms of the pancreas. Gastroenterology 1987; 92: 1934-1943

45 Walsh RM, Henderson JM, Vogt DP et al. Prospective preoperative determination of mucinous pancreatic cystic neoplasms. Surgery 2002; 132: 628 - 33; discussion 633-634

46 Frossard JL, Amouyal P, Amouyal G et al. Performance of endosonography-guided fine needle aspiration and biopsy in the diagnosis of pancreatic cystic lesions. Am J Gastroenterol 2003; 98: 1516-1524

47 Brugge WR, Lewandrowski K, Lee-Lewandrowski E et al. Diagnosis of pancreatic cystic neoplasms: a report of the cooperative pancreatic cyst study. Gastroenterology 2004; 126: 1330-1336

${ }^{48}$ Hammel P, Voitot H, Vilgrain V et al. Diagnostic value of CA $72-4$ and carcinoembryonic antigen determination in the fluid of pancreatic cystic lesions. Eur J Gastroenterol Hepatol 1998; 10: 345 - 348

49 van der Waaij LA, van Dullemen HM, Porte RJ. Cyst fluid analysis in the differential diagnosis of pancreatic cystic lesions: a pooled analysis. Gastrointest Endosc 2005; 62: 383 - 389

50 Zhou GX, Huang JF, Li ZS et al. Detection of K-ras point mutation and telomerase activity during endoscopic retrograde cholangiopancreatography in diagnosis of pancreatic cancer. World J Gastroenterol 2004; 10: 1337 - 1340

51 Telford JJ, Carr-Locke DL. The role of ERCP and pancreatoscopy in cystic and intraductal tumors. Gastrointest Endosc Clin N Am 2002; 12: $747-757$

52 Dachman AH, Namieno T, Ichimura T et al. Mucin-producing pancreatic tumors: comparison of MR cholangiopancreatography with endoscopic retrograde cholangiopancreatography. Radiology 1998; 208: 231 - 237

${ }^{53}$ Koito K, Namieno T, Ichimura T et al. Mucin-producing pancreatic tumors: comparison of MR cholangiopancreatography with endoscopic retrograde cholangiopancreatography. Radiology 1998; 208: 231 - 237

54 Sugiyama M, Atomi Y, Saito M. Intraductal papillary tumors of the pancreas: evaluation with endoscopic ultrasonography. Gastrointest Endosc 1998; 48: $164-171$

55 Kobayashi G, Fujita N, Noda Y et al. Mode of progression of intraductal papillary-mucinous tumor of the pancreas: analysis of patients with follow-up by EUS. J Gastroenterol 2005; 40: 744-751

${ }^{56}$ Irie H, Yoshimitsu K, Aibe $\mathrm{H}$ et al. Natural history of pancreatic intraductal papillary mucinous tumor of branch duct type: follow-up study by magnetic resonance cholangiopancreatography. J Comput Assist Tomogr 2004; 28: 117 - 122

57 Gan SI, Thompson CC, Lauwers GY et al. Ethanol lavage of pancreatic cystic lesions: initial pilot study. Gastrointest Endosc 2005; 61: $746-$ 752

58 Kimura W, Makuuchi M. Operative indications for cystic lesions of the pancreas with malignant potential - our experience. Hepatogastroenterology 1999; 46: $483-491$

59 Fernandez del Castillo CF, Targarona J, Thayer SP et al. Incidental pancreatic cysts: clinicopathologic characteristics and comparison with symptomatic patients. Arch Surg 2003; 138: 427-434

60 Le Borgne J, de Calan L, Partensky C. Cystadenomas and cystadenocarcinomas of the pancreas: a multiinstitutional retrospective study of 398 cases. French Surgical Association. Ann Surg 1999; 230: 152 - 161

61 Gigot JF, Deprez P, Sempoux C et al. Surgical management of intraductal papillary mucinous tumors of the pancreas: the role of routine frozen section of the surgical margin, intraoperative endoscopic staged biopsies of the Wirsung duct, and pancreaticogastric anastomosis. Arch Surg 2001; 136: 1256-1262 
${ }^{62}$ Chari ST, Yadav D, Smyrk TC et al. Study of recurrence after surgical resection of intraductal papillary mucinous neoplasm of the pancreas. Gastroenterology 2002; 123: 1500-1507

${ }^{63}$ Spinelli KS, Fromwiller TE, Daniel RA et al. Cystic pancreatic neoplasms: observe or operate. Ann Surg 2004; 239: 651 -7; discussion 657-659

${ }^{64}$ Sohn TA, Yeo CJ, Cameron JL et al. Intraductal papillary mucinous neoplasms of the pancreas: an updated experience. Ann Surg 2004; 239 : 788-97; discussion 797-799

${ }^{65}$ Lai EC, Lau WY. Intraductal papillary mucinous neoplasms of the pancreas. Surgeon 2005; 3: $317-324$

${ }^{66}$ Falconi M, Salvia R, Bassi C et al. Clinicopathological features and treatment of intraductal papillary mucinous tumour of the pancreas. Br J Surg 2001; 88: 376 - 381

${ }^{67}$ Suzuki Y, Atomi Y, Sugiyama M et al. Cystic neoplasm of the pancreas: a Japanese multiinstitutional study of intraductal papillary mucinous tumor and mucinous cystic tumor. Pancreas 2004; 28: 241 - 246

${ }^{68}$ Kobari M, Egawa S, Shibuya K et al. Intraductal papillary mucinous tumors of the pancreas comprise 2 clinical subtypes: differences in clinical characteristics and surgical management. Arch Surg 1999; 134: $1131-1136$ 